\title{
Oxleas NHS Rehabilitation Service Redesign and Staff Wellbeing: A Case Study of Ivy Willis House
}

\section{Waheed Azeez ${ }^{*}$}

London School of Business and Computer, University of East London, 58 Camden Hill Road, UK

\begin{abstract}
There is no disputing the fact that the UK's National Health Service (NHS) is currently in deep financial trouble. With steady increase in the population and increasing demands on its services, the pressure on all the NHS trusts continues to increase day-by-day. Despite all these, the country still grapples with its own economic problems which make it extremely difficult to provide enough money needed to fund the NHS. Owing to the importance of health care to national development, the UK public is not ready to compromise its demand for quality health services that must be free at the point of delivery. As the prime minister pointed out in one of her TV interviews, there is no magic tree from which money could be plucked endlessly to fund the NHS services. The government however considered it necessary to cut funding to public sector services to fill the hole in the economy. This translated into pressures mounted on all government departments to cut their expenses and the NHS is not exempted. Different NHS trusts responded differently. For example, Oxleas NHS Foundation Trust responded by redesigning many of its services and directorates to devise a new way of working in a smart, efficient and less expensive way. The aim of this paper is to look into one of these redesign programmes with a view to evaluate its impacts on staff welfare.
\end{abstract}

Keywords: Rehabilitation; Government; Crisis; Framework

\section{Introduction}

Since the Tories came to power in June 2010 the government has embarked on a massive drive to cut down on public expenses with the aim to bring the economy back on track and reduce budget deficit year in year out. Financial allocations to the local councils and other governments departments and parastatals have since been drastically reduced continually. Initially, the government promised to exempt the NHS from these cuts but rather increase allocation to the health service to save it from imminent collapse. However, as events unfolded and the NHS debts continued to increase due to high demands on its services, politicians started to change their rhetoric to justify hospital closures and reduction in services. From 201066 A\&E and other units have badly been hit by cuts. Those affected have either been closed or downgraded since 2010 and many more are now under threat [1]. As the government continues to mount pressure on the NHS to cut down its expenses, different NHS trusts respond differently. For instance, Oxleas NHS Foundation Trust responded by redesigning some of its services to implement money saving strategies and improve service delivery. This redesign exercise involves closing or merging of units and departments, staff retraining and redeployment, relocation and reorganisation of services. The objective of this project is to assess Oxleas service redesign exercise and its effects on staff welfare focusing mainly on the staff working at Ivy Willis House. Although many units and departments were affected by this exercise, we have chosen Ivy Willis House because this unit has the highest number of staff affected by this process. At the end of the project, we will be able to establish whether this process has any positive or negative impacts on staff welfare.

\section{Previous Service Structure}

Previously Oxleas services were divided into six directorates. These are Adult Community Services, Adult Mental Health and Learning Disability Services, Children and Young People's Services, Corporate services, Forensic and Prison Services and Older People's Mental Health Services. Each directorate was subdivided into different service hubs and each service hub consisted of units and teams. For instance, the Inpatient, Rehabilitation and Crisis is a unit under the Adult Mental Health and Learning Disability Services. The unit itself includes inpatient units at Green Parks House (Princess Royal University Hospital), Woodlands Unit (Queen Mary's Hospital) and Oxleas House (Queen Elizabeth Hospital) and A\&E Psychiatric Liaison Services at Queen Elizabeth Hospital and Green Parks House. Also included in this service hub were the four rehabilitation units, namely Barefoot Lodge, Summerset Villa and Ivy Willis House. All these units provided rehabilitation services for patients discharged from the acute wards who were considered unsuitable for independent living in the community. Ivy Willis House had two units, the open unit and the close unit.

\section{Ivy Willis House open}

The open unit of Ivy Willis House was a specialist multi-disciplinary service for individuals suffering from long-term and enduring mental ill health. The team formed part of a planned and integrated whole system approach to care that was delivered in conjunction with inpatient, crisis and specialist services. The service offered by Ivy Willis House was based on recovery model principles and good practice guidelines outlined in the National Service Framework for Mental Health (NSF). The service provision is aimed at individuals who are experiencing severe and enduring mental health difficulties requiring rehabilitation input [2]. Ivy Willis Open unit is a 17 bedded rehabilitation ward serving the Borough of Bromley. The unit caters for male and female adults aged between 18-64 years. However, service users may stay on

*Corresponding author: Waheed Azeez, London School of Business and Computer, University of East London, 58 Camden Hill Road, Tel: +7897976469; E-mail: onilenla60@yahoo.com

Received October 02, 2017; Accepted October 09, 2017; Published October 13, 2017

Citation: Azeez W (2017) Oxleas NHS Rehabilitation Service Redesign and Staff Wellbeing: A Case Study of Ivy Willis House. Arts Social Sci J 8: 307. doi: 10.4172/2151-6200.1000307

Copyright: () 2017 Azeez W. This is an open-access article distributed under the terms of the Creative Commons Attribution License, which permits unrestricted use, distribution, and reproduction in any medium, provided the original author and source are credited. 
over the age of 65 if they are engaged in the Rehabilitation treatment process [3]. The unit is situated in Anerley.

\section{Ivy Willis House closed}

The closed unit of Ivy Willis House on the other hand was specialist multi-disciplinary service for individuals suffering from long-term and enduring mental ill health. The team formed part of a planned and integrated whole system approach to care that was delivered in conjunction with inpatient, crisis and specialist services. The service offered by the Ivy Willis was also based on recovery model principles and good practice guidelines outlined in the National Service Framework for Mental Health. The service provision was aimed at individuals who were experiencing severe and enduring mental health difficulties requiring rehabilitation input. Ivy Willis closed unit was a 13 bedded low/medium secure bed serving Bromley Borough. The unit catered for 13 male adults aged between 18-64 years. 11 beds were commissioned by Bromley borough and 2 beds were meant for income generation. However, service users might stay on over the age of 65 if they were engaged in the Rehabilitation treatment process. Both the open and the closed units were based in Anerley in the same building named Ivy Willis House. The units were separated by a single door and were both managed by only one manager. The charts below show an overview of staff distribution for each of the two units (Tables 1 and 2). Posts not included in these structure charts were Medical and Psychology establishments as posts were split between Adult Mental Health Community, Inpatient and Rehab Services.

\section{Reason for change}

Financial consideration was cited as the main driver for the redesign programme. According to the initial consultation paper submitted on the programme, the Trust was not in the best financial state and something must be done to avert any imminent negative cash flow. The trust's directorate was of the opinion that, in order to remain within the trust's financial envelope, the managers needed to utilise the available resources in the most efficient way by adhering to required efficiency savings. However, there were other less pronounced drivers

\begin{tabular}{|l|l|c|c|c|}
\hline Ward & Post & $\begin{array}{c}\text { Establishment } \\
\text { WTE }\end{array}$ & $\begin{array}{c}\text { WTE in } \\
\text { post }\end{array}$ & $\begin{array}{c}\text { No. of actual } \\
\text { staff in post }\end{array}$ \\
\hline Ivy Willis Open & Nurse Band 6 & 2 & 2 & 2 \\
\hline Ivy Willis Open & Nurse Band 5 & 9 & 7 & 7 \\
\hline Ivy Willis Open & Nurse Band 3 & 5 & 5 & 5 \\
\hline Ivy Willis Open & Nurse Band 2 & 4 & 2 & 2 \\
\hline Ivy Willis Open & OT Band 6 & 1 & 1 & 1 \\
\hline Ivy Willis Open & OT Band 3 & 1.03 & 1 & 1 \\
\hline & Total & $\mathbf{2 2 . 0 3}$ & $\mathbf{1 8}$ & $\mathbf{1 8}$ \\
\hline
\end{tabular}

\begin{tabular}{|l|l|c|c|c|}
\hline Ward & Post & $\begin{array}{c}\text { Establishment } \\
\text { WTE }\end{array}$ & $\begin{array}{c}\text { WTE in } \\
\text { post }\end{array}$ & $\begin{array}{c}\text { No. of actual } \\
\text { staff in post }\end{array}$ \\
\hline Ivy Willis Closed & Nurse Band 8A & 1 & 0 & 0 \\
\hline Ivy Willis Closed & Nurse Band 6 & 3 & 3 & 3 \\
\hline Ivy Willis Closed & Nurse Band 5 & 8 & 6 & 6 \\
\hline Ivy Willis Closed & Nurse Band 3 & 5 & 4 & 4 \\
\hline Ivy Willis Closed & Nurse Band 2 & 4 & 1 & 1 \\
\hline Ivy Willis Closed & OT Band 6 & 1 & 1 & 1 \\
\hline Ivy Willis Closed & OT Band 3 & 1 & 1 & 1 \\
\hline Ivy Willis Closed & A\&C Band 3 & 1 & 1 & 1 \\
\hline Ivy Willis Closed & ASC Band 3 & 1 & 0 & 0 \\
\hline & Total & $\mathbf{2 5}$ & $\mathbf{1 7 . 0 0}$ & $\mathbf{1 7}$ \\
\hline
\end{tabular}

Table 2: Ivy Willis Closed Staff Details. to this change. For instance, in recent years, there has been a gradual but continual movement towards increased community models of care to enable patients to recover in the least restrictive settings with moderate staff support [4]. In addition to that, the real desire to see patients moving into more independent living with wider and more varied packages of support has always been echoed across the NHS [5]. The proposed changes were therefore expected to further enhance the community reorganisation. More importantly, the Trust has always been engaging in creating more standardised care pathways which would eventually necessitate the need to change the way care services were managed and delivered. Moreover, as one of the leading mental and community health services in the country, covering the boroughs of Greenwich and Bexley and Bromley, Oxleas must be prepared to face new challenges at the front line and these challenges include unprecedented population growth in all the three boroughs which in turn places services under increasing demand. People are also living longer and making greater use of a range of health and social care services. All these developments exacerbated the need to adopt new approaches both to service delivery and to supporting service users in managing their own health. As stated in the board paper published in November, 2016, the trust's policy makers believed that the following were to be attained through the redesign exercise:

- A faster recovery for patients and a faster return to independence;

- Improved outcomes for patients;

- Creation of an improved and more consistent patient experience of rehabilitation across Oxleas;

- Creation of a seamless transition between acute hospital care and community care and between health and social care;

- Inpatient accommodation which is fit for purpose, meeting requirements for health and safety, privacy and dignity and promotes wellbeing and recovery;

- Improved satisfaction;

- Improved performance;

- Reduction in the delayed transfer of care/transfer pressures;

- Reduction of external placements;

- Improved relationships with stakeholders.

\section{The New Model and Structure}

Prior to the start of the redesign process, the trust had four rehabilitation units spread across two boroughs of Bexley and Bromley. In Bexley, there were Barefoot Lodge and Somerset Villa. Both of the units were situated within the same neighbourhood making it easy for staff and service users to interact, collaborate and do things together. The other two situated in Bromley were housed under the same roof. Both units were referred to as Ivy Willis House. However, each of them provided slightly different forms of rehabilitation services which we have described above. As the objective of the programme was to encourage community-based treatment as against the inpatient services, it was decided that 3 of the units should be closed living only one open. Only Barefoot Lodge was left open while the remaining three units were closed. The following table shows the composition of staff at Barefoot Lodge: In order to make-up for the gap created by the closure of the remaining three rehabilitation units, a new module called Community Mental Health Rehabilitation and Enablement 
Service (CMHRES) was created with the aim to play an essential role in supporting patients transition through the various care pathways namely from hospital to community settings and from higher to less supported accommodation. This led to the emergence of 3 borough based teams which started operation fully on $28^{\text {th }}$ March. The following charts illustrate the borough based structure and the staff distribution within the structure (Tables 3 and 4).

\section{How staff were affected}

The process for the redesign programme was carefully monitored by this writer. What we have observed was that the directorate tried to comply with the law throughout the period of redesign, especially in relation to ACAS guidelines on redundancy, including fairness in selection for redundancy, redundancy pay, notice periods, consultation, suitable alternative employment and providing help finding a new job. The consultation started as soon as the trust decided to go ahead with the redesign. All the affected staff were informed by writing and consultation meetings were held to intimate staff with the entire process. Following formal consultation and the circulation of the outcome paper, all staff were given to apply for the roles both at Barefoot Lodge and within the community rehabilitation model. Those who were unsuccessful were then placed "at risk". The guideline stipulated that those staff who were unsuccessful in obtaining any of the roles within rehabilitation should be given suitable alternative employments. A post might be considered as suitable alternative employment if it was banded on the same band as the staff member's current post or one band lower in accordance with the NHS banding system. The protection of pay arrangements for

\begin{tabular}{|c|c|}
\hline Grade & Establishment WTE \\
\hline 7 & 1 \\
\hline 6 & 2 \\
\hline 5 & 7 \\
\hline 2 & 10 \\
\hline Psychologist & 1 \\
\hline OT & 1 \\
\hline OT-TI Band 3 & 0.5 \\
\hline Admin Band 3 & 1 \\
\hline Cook Band 2 & 0.53 \\
\hline
\end{tabular}

Table 3: Barefoot Lodge Staff Details. staff on Agenda for Change (AfC) terms and conditions are outlined in the Trust's Managing Organisational Change policy [6]. However, those staff who were employed on fixed-term contracts whose contracts ended prior to implementation were not included in selection pools or slotted into the new structures.

\section{Impacts on Staff Wellbeing}

As can be gathered from the above, employees working at Ivy Willis House were mostly affected by this redesigned programme. We have mentioned earlier that, of all the four inpatient rehabilitation units operated by Oxleas, only one was retained at the conclusion of the project and the spared unit is Barefoot Lodge. Basically, Somerset Villa and Ivy Willis House were both closed. Somerset Villa was closed in September 2016 while Ivy Willis House was closed on $27^{\text {th }}$ February 2017. That means that there was a gap of six months between the closure of the former and the latter. The implication of this is that staff working at Somerset Villa had more time to look for alternative employment as they had been put at risk long before their counterparts at Ivy Willis House. Moreover, Ivy Willis House had more staff than the other sites. We must not forget that it comprised two separate units each of the units providing different types of rehabilitation services. So, while staff at Somerset were already being helped and supported to find alternative employments, Ivy Willis staff were still busy providing regular services to the patients. This kind of arrangement gave an upper hand to some members of staff against the other as they stood a better chance of being employed more quickly than their colleagues. The stress and anxiety levels of the affected staff are the main focus of this writer. Selected staff members were interviewed informally and those interviewed were randomly selected to represent the views other members of staff. 10 employees were interviewed in this exercise. One of them is the unit manager, a doctor, two qualified nurses, 2 therapists, 2 technical instructors and two health care assistants. All of them agreed that they wished the redesign had not taken place. None of those interviewed felt it was a positive experience for them. $60 \%$ of them thought the move was justified.70\% declared that the redesign process raised their stress levels. $60 \%$ wished the old structure returned to. Only 50\%, however, expressed confidence in the entire process. On the question whether the employer's handling of the whole process fair, only $40 \%$ said yes, $30 \%$ said no and $30 \%$ were neutral. Information gathered from affected

\begin{tabular}{|c|c|c|c|c|c|c|}
\hline & \multicolumn{2}{|c|}{ Bromley } & \multicolumn{2}{|c|}{ Greenwich } & \multicolumn{2}{|l|}{ Bexley } \\
\hline Service provision & \multicolumn{2}{|c|}{ Multi-disciplinary CMHRES Team } & \multicolumn{2}{|c|}{ Multi-disciplinary CMHRES Team } & \multicolumn{2}{|c|}{ Multi-disciplinary CMHRES Team } \\
\hline Hours & \multicolumn{2}{|c|}{$\begin{array}{l}\text { Monday to Friday } 9 \text { am to } 5 \mathrm{pm} \text { core hours, } \\
\text { with extended hours developed in response to } \\
\text { clinical need } \\
9 \text { am to } 5 \mathrm{pm} \text { core hours, with extended hours } \\
\text { developed in response to clinical need }\end{array}$} & \multicolumn{2}{|c|}{$\begin{array}{l}\text { Monday to Friday } 9 \text { am to } 5 \text { pm core hours, with } \\
\text { extended hours developed in response to clinical need }\end{array}$} & \multicolumn{2}{|c|}{7 days a week 8 am to $8 \mathrm{pm}$} \\
\hline Focusing on & \multicolumn{2}{|c|}{$\begin{array}{l}\text { Service users in various levels of care from } \\
\text { hospital through to own tenancy }\end{array}$} & \multicolumn{2}{|c|}{$\begin{array}{l}\text { Service users in various levels of care from hospital } \\
\text { through to own tenancy }\end{array}$} & \multicolumn{2}{|c|}{$\begin{array}{l}\text { Service users in various levels of care from } \\
\text { hospital through to own tenancy } \\
\text { Service users in various levels of care from } \\
\text { hospital through to own tenancy }\end{array}$} \\
\hline \multicolumn{7}{|l|}{ staffing } \\
\hline \multicolumn{7}{|c|}{ 1.00 WTE Band 8a Manager Across The Three Borough CMHRES Service } \\
\hline Medical & TBC & & TBC & & TBC & \\
\hline Psychology & Band $8 \mathrm{a}$ & 0.5 WTE & Band $8 a$ & 0.4 WTE & Band $8 a$ & 0.5 WTE \\
\hline \multirow[t]{2}{*}{ OT } & Band 6 & 0.6 WTE & Band 6 & 1.00 WTE & Band 6 & 1.00 WTE \\
\hline & Band 3 & 1 WTE & Band 3 & 0.5 WTE & N/A & N/A \\
\hline Manager & & & Band 7 & 1.00 WTE & Band 7 & 1.00 WTE \\
\hline CPNs & Band 6 & 3.00 WTE & Band 6 & 3.00 WTE & Bad 6 & 4.00 WTE \\
\hline Support Workers & Band 3 & 2.00 WTE & Band 3 & 2.00 WTE & Band 3 & 3.00 WTE \\
\hline
\end{tabular}

1.00 WTE Band 3 Administrator Across The Three Borough CRS Service

Table 4: Illustrate the borough based structure and the staff distribution within the structure. 
staff as stated above shows that staff's experience during and after the redesign exercise was overall negative. This is not because the employer did not stay within the law during the process, but their attitude shows that they did not have the interest of staff in their hearts as often claimed. At the beginning of the whole process, the Human Resources department told staff that no one would be placed on redundancy no matter the situation or circumstances of the staff. Given the fact that some employees were in unique circumstances, taking this kind of decision is cruel, irresponsible and illegal. As of the time of writing this report, not less than five members of staff have still not been offered suitable alternative employments. Besides, it is clearly stated in the consultation paper that "Staff will have a right of appeal against the decision to terminate their contract for reason of redundancy." For the HR to turn around and insist that no redundancy payment would be paid amounts to a breach of contract. As gathered through the interviews, staff experienced a very high level of anxiety during the redesign process. $60 \%$ of staff interviewed said they felt stressed or anxious during the process and only $40 \%$ said they were satisfied with the level of support provided. Even, the senior management team itself recognised the process undoubtedly caused some concern and anxiety for staff. One member of management confirmed that absence due to sickness increased tremendously and was on record high during the redesign process. There also was an increase in attacks from patient to staff in the weeks leading the conclusion of the process. This sparked a safety concern among the employees.

\section{The Role of the Trade Unions}

There is no doubt that the main objective of trade unions is to defend the interests of their members and to protect them from any form of abuse from employers. Failure to represent and support fee paying members amount to breach of contract between a trade union and its members. That is why, the author suggests community unionism as the best strategy that trade unions in industrialised economies can adopt to win the heart of their members and protect their interests effectively. Another important function of the trade union is collective bargaining which serves as a form of empowerment for the individual employees to support them in the course of any negotiation with employers. It is quite evident that this type of collective bargaining is necessary during the process of redundancy. According to ACAS, trade unions must be consulted during the course of any redundancy procedure [7]. In view of the above, it should be expected for trade union members within the trust to be represented in all negotiations affecting them. Failure to this would be a contravention of the Trade Union Act (1992/2016). As a result of this, the trust's management made sure that representatives of all the trade unions within trust were carried along throughout the redesign exercise so that they could protect the interests of their members [8]. This claim was made by the HR Manager, Denise Braddon in a meeting with some affected employees on $8^{\text {th }}$ August 2016. In a meeting held on $2^{\text {nd }}$ February, all union leaders in the trust expressed their satisfaction in the manner in which the redesign was concluded. However, most of the affected employees who were union members painted a different scenario $[9,10]$. 10 of them were randomly selected for interviewing. It is staggering to note that only three of those interviewed said they were satisfied with the support they received from their unions. When presented with this result, the head of the Staff side committee representing all the unions in the trust responded that such responses should be expected owing to the current political and economic climates in which the government is striving to erode the rights of the employees in favour of the employers. For instance, major amendments were made to the Trade Union Act of
1992 which metamorphosed into the Trade Union Act of 2016. Some of the statutory rights enjoyed by employees have been removed while the powers of trade unions have been weakened drastically [11].

\section{Conclusion}

NHS is one of the largest employers in the United Kingdom. Being a leading public service organisation in the country, it is her responsibility to look after the welfare of its workforce, especially the doctors, nurses, therapists and other frontline workers who dedicate their time and energy to keep the organisation afloat. However, wallowing in large debts, coupled with pressure from the government to cut down its expenses, the organisation struggles to survive in the current financial climate amid an increase in demand for its services. As the NHS tries hard to keep up with all these challenges, it is the employees that bear the brunt. Managers often find it easy to lay off some employees and place some on redundancy to save money. It is in the spirit of this that we have decided to study a redesign project that took place in one of the leading NHS trusts in the South East England so that we can understand what effects this type of project affect staff and what impacts, positive or negative does it have on their wellbeing. Although our study was directed to the redesign of the rehabilitation services in Oxleas NHS Foundation Trust, focusing on Ivy Willis House, it is our belief that similar findings would be made if the study were to any other unit or trust within the country. Our findings show that the redesign exercise has caused a lot of anxiety for the affected staff because they are not entirely happy with the whole idea. It has increased stress levels among staff members making them susceptible to unpalatable mental state such as depression, paranoia etc. With the same process currently taking place in various trusts within the NHS, it is likely that the safety of the service users may be compromised. If this trend continues, more qualified staff will leave the NHS and use their skills abroad. Those stay in the country may decide to work as agency staff making the NHS spend more money rather save money. Above all, a demoralised workforce cannot provide the high-quality service that the NHS desires to provide. That is why the NHS must try to raise the morale of its employees to improve productivity, service quality and patient satisfaction.

\section{References}

1. Laura Donnelly (2014) The-List of 66 A and E and Maternity Units B being Hit by Cuts.

2. Thornicroft G (2000) National Service Framework for mental health. The Psychiatrist 24: 203-206.

3. James H and Jackie P (2014) Bronley Change Management Programme for Adult and Older Adult Services.

4. Oxleas (2016) 110th Meeting of the Board of Directors.

5. Darzi A (2007) NHS next stage review: interim report COI for the Department of Health.

6. Mc Gabhann L, Baker S, Dixon P (2002) Prevention and management of violence: implementing clinically effective practice. Mental Health Practice 6: 8-13.

7. ACAS (2017) Redundancy Handling Available.

8. Azeez W (2015) Improving Customer Experience in Mental Health Service: A Case Study of Ivy Willis House International Journal of Advanced Multidisciplinary Research and Review.

9. BBC (2015) David Cameron renews NHS funding pledges.

10. Davey B and Dix G (2011) The dispute resolution regulations two years on: The Acas experience ACAS research paper 7: 11

11. Gospel H, Lockwood G, Willman P (2000) A British dilemma: disclosure of information for collective bargaining and joint consultation Comp Lab L \& Pol'y J 22: 327 